\title{
Difference Between Perceptions Of Preceptors And Newly Graduated Nurses Regarding Delay In Professional Growth: A Thematic Analysis
}

Chihiro Kawakami ( $\nabla$ uribou@gifu-u.ac.jp )

Gifu University

Rintaro Imafuku

Gifu University

Takuya Saiki

Gifu University

\section{Research Article}

Keywords: nursing practice, delay in growth, preceptor, difference of perceptions, preceptee, nursing education

Posted Date: February 21st, 2022

DOI: https://doi.org/10.21203/rs.3.rs-1333945/v1

License: (c) (i) This work is licensed under a Creative Commons Attribution 4.0 International License. Read Full License 


\section{Abstract}

Background: Smooth reciprocal relationships enable the preceptee's growth, and it has been suggested that without such relationships, the preceptee may not be able to grow successfully. This study explored the differences in perceptions by matching the perspectives of both the preceptee and the preceptor who did not make progress in workplace adjustment. Identifying the differences in perceptions between the two groups is important for improving nurse education and the relationship between preceptees and preceptors.

Methods: A pair of nurses who had been with the company for less than three years, of which, those who had previously been transferred or had resigned due to poor workplace adjustment were designated as preceptees, and those who had directly supervised the preceptee during their first year of employment were included as preceptors in the study. A 50-minute semi-structured interview was conducted separately to examine the perceptions of the preceptee and preceptor. A thematic analysis was used to analyze the interview data.

Results: This study explored the differences in perceptions regarding the clinical practice of nursing between preceptors and their preceptees, who did not make progress in workplace adjustment during nurse education; six themes were identified. After interviewing both sides, it became clear that the same event was interpreted differently depending on their positions, perspectives, and contexts. As the preceptees were nurses who had left or had been transferred, the existence of these differences in perceptions suggests that these factors may have an impact on their departure or transfer. However, we do not aim to place blame on one side or the other for the preceptee's turnover or transfer and would like to consider effective support not only for the preceptee but also for the preceptor.

Conclusions: It is necessary to examine nurse education on the premise that such differences may occur depending on the position and role of nurses in the workplace, and to look at curricular framework changes to bring in a systemic influence towards the training of young nurses.

\section{Background}

Training newly recruited medical personnel is an important objective in medical education. In the medical field, it is essential to secure and train stable nurses to provide appropriate treatment and care for patients. In the field of nursing, preventing the early turnover of nurses within the first year of employment is an urgent issue [1, 2]. However, currently in Japan, about $10 \%$ of new nurses leave the workforce earlywithin one year of starting work $[3,4]$.

In general, the reasons nurses leave their jobs include organizational factors, such as the work environment and organizational culture, and personal factors, such as job satisfaction and burnout; these factors are complex and intertwined [5]. Factors related to the preceptor (hereinafter referred to as "preceptor" for nurses who are educators) include psychological burden [6], problems related to nursing practice ability [7], reality shock [8] after joining the company, and organizational factors such as human 
relations and work environment $[9,10]$, all of which may lead to turnover. In order to prevent such early turnover, the presence of a preceptor who supports the personal needs of newly hired nurses (hereinafter referred to as "preceptee" for new and young nurses) in the workplace and develops their nursing practice skills is vital. However, in reality, there are many preceptors who have difficulty dealing with preceptees $[11,12]$. Preceptors find it difficult to comprehend the level of understanding of the preceptees and to communicate smoothly according to the situation [13]. Thus, providing individualized guidance to new nurses is difficult [14].

To develop effective nursing education, it is important to examine the relationship-building process and perceptions of practice between preceptors and preceptees from their perspectives. However, studies from such a comprehensive perspective are limited. In extant studies, when the preceptor and the preceptee were surveyed about their satisfaction with the preceptorship, their job satisfaction was high, and the preceptor's strength was reflected in the preceptee's ability to fit in with the new unit, teach, and share knowledge. Conversely, the preceptee indicated interpersonal relationships, communication, and professional development as strengths of the preceptor, and teaching, collaboration, and critical care as weaknesses [15]. They also stated that it is important for the personal characteristics and learning styles of both parties to match [15]. In one study that explored the perceptions, experiences, and needs of both preceptees and preceptors regarding preceptorship, it was found that the social role of the preceptor, providing autonomy to preceptees, communication and the use of technology, involvement of nursing managers, and learning styles were the most important factors [16]. Further, it was noted that the relationship between the preceptor and the preceptee was important, and when the preceptor was relationship-oriented, the preceptee's independence was hindered, and when the preceptor was taskachievement-oriented, the relationship was tense, and the feedback was critical [16]. Smooth reciprocal relationships enable the preceptee's growth, and it has been suggested that without such relationships, the preceptee may not be able to grow successfully.

This study explored the differences in perceptions by matching the perspectives of both the preceptee and the preceptor who did not make progress in workplace adjustment. Identifying the differences in perceptions between the two groups is important for improving nurse education and the relationship between preceptees and preceptors.

\section{Methods}

\section{Participants}

A pair of nurses who had been with the company for less than three years, of which, those who had previously been transferred or had resigned due to poor workplace adjustment were designated as preceptees, and those who had directly supervised the preceptee during their first year of employment were included as preceptors in the study. 
We recruited participants with the cooperation of the Department of Nursing at two teaching hospitals with 600 or more beds. To be eligible for participation, nurses had to be qualified but exhibit a delay in professional growth for the first three years. In most hospitals in Japan, the Department of Nursing utilizes a three-year training program following the employment of newly qualified nurses as a means for developing nurses. To determine whether a nurse is competent, both teaching hospitals employ the training guidelines of the Japanese Nursing Association's (JNA) Clinical Ladder [17]. In this study, we defined delayed professional growth as the nurse not meeting the standards outlined in the JNA Clinical Ladder training guidelines within three years of employment, as judged by their instructors and nurse directors, resulting in their resignation or transfer to another division. Here, we termed nurses with delayed professional growth as preceptees. The person who was in charge of educating that preceptee in the first year was designated as the preceptor, and the pair was targeted.

After obtaining informed consent verbally, the Department of Nursing scheduled interviews with each participant. The author (the interviewer) was introduced to the participants on the day of the interview. The author explained the study objectives prior to obtaining the respondents' written consent in order to ascertain their will to participate in the interview.

Ten pairs of participants from the two teaching hospitals participated, comprising a total of 20 participants.

\section{Ethical considerations}

This study was approved by the Institutional Review Board of Gifu University. (Approval Number 25385). As for the content of the preceptors' and preceptees' interview comments on the preceptees' work performance, confidentiality was assured.

\section{Data collection}

A 50-minute semi-structured interview was conducted separately to examine the perceptions of the preceptee and preceptor. In the interview, the preceptors were asked about memorable events in their corresponding preceptee's nursing clinical practice (work). The preceptees were also asked about memorable events in their nursing clinical practice (work). The interview guide is as follows:

Preceptee

"Looking back on your clinical nursing practice (work) in your first year of employment, is there anything that left a strong impression on you?

Please tell us specifically about this event.

- What do you think were the positives/negatives (cause) of the event?

- How did you feel about the incident?"

Preceptor 
"Are there any memorable events in the preceptee's nursing clinical practice (work)?

Please tell us specifically what happened.

- What do you think were the positives/negatives (cause) of the event?

- How did you feel about the incident?"

\section{Data analysis}

A thematic analysis was used to analyze the interview data [18]. Two researchers (CK, TS) independently read the transcripts several times to understand the text, found the keywords in the text, coded the data from the keywords, and finally, organized these codes into themes by repeatedly discussing the initial theme to modify and integrate the final theme. The validity of the analysis was verified by another researcher (RI) through a discussion of the final themes until a consensus was reached.

\section{Results}

\section{(1) Participants}

Through the nursing departments of the two university-affiliated hospitals, the researcher asked the ward managers to name the target pairs, obtained the informal consent of both pairs, explained the results to them, and obtained their written consent. Consequently, 10 pairs consented to the study. The status of each pair is described below (Table 1).

$\bigotimes$ Table 1 The status of preseptees and preseptors $₫$ insert

(2) Difference in perception between the preceptee and the preceptor

From the interviews, the following six themes were extracted about the perceived differences between preceptees and preceptors regarding the former's clinical practice:

Theme 1: Preceptee's ability to carry out their work

Theme 2: Directing preceptee's awareness (attention) during work

Theme 3: The ability of the preceptee to apply knowledge

Theme 4: Preceptee's self-evaluation ability

Theme 5: The nature of communication in the learner-instructor relationship

Theme 6: Conducting business in a collaborative manner

Next, we summarize the definitions by themes and the descriptions of the preceptee and preceptor pairs. The following table summarizes characteristics of the pairs that showed cognitive 
differences in Themes 1 to 6 across both interviews (Table 2).

$<$ Table 2 Emergence of a theme for each pair》 insert

Theme 1: Preceptee's ability to carry out their work

Definition of Theme 1

Performing nursing clinical work in a methodical manner is important, and both parties recognized that this requires good handedness, manual dexterity, and the ability to learn to complete the work in a timely manner. Generally speaking, with practice and experience, a person can gradually improve their ability to perform the job and complete it in less time. However, both parties understand that an inexperienced and unaccustomed preceptee's job performance may neither be adequate nor timely; compared to the nurses that the preceptor has taught in the past, this preceptee might be taking longer than is acceptable.

Sub-theme (1): Perceived differences in manual dexterity when performing tasks

Both pairs were aware of the preceptee's manual clumsiness.. However, the preceptee had a hard time accepting this lack of manual dexterity, exhibited a strong desire to improve, and often felt impatient, saying "I can do it" when unable to do something.

In contrast, the preceptor felt that the preceptee is too clumsy and takes more time than assumed; this feeling can be regarded as dismay. In addition, the preceptor judged the workflow as "disorganized" and "not memorized."

Pair E

Preceptee

"When I was doing detailed work, I was awkward or not to the point, or maybe I am not good at detailed manual skills (I think). I thought it was natural that my level would increase after the first year, but I could not do it. I could not admit that I could not do it because I saw my peers who were doing so well. I did not want to admit that I could not do it. I was so impatient that I did not want to drop out, so I said that I will do it even when I could not do it. I thought I was being too tall for my own good."

Preceptor

"She/he was very clumsy with her/him hands; for example, a pubic wash would take 40-50 minutes. She/he was so nervous and sweaty that she/he could not put the gloves properly, and the items were not properly positioned-the patient kicked and spilled them; she/he could not connect the instruments properly for the intravenous drip or the blood collection. It was like she/he could not do it smoothly and it was a mess. In the end, I think she/he did not remember the procedures perfectly, and in April (right after she joined), she/he already had a gap with her peers, which we both knew and were worried about." 
Sub-theme (2): Differences in perceptions of time allocation and pace of completing tasks

Both pairs were aware that it takes the preceptee a very long time to complete the day's work. The preceptee was aware that this was due to the fact that there were many tasks. In addition, the preceptee was underinformed about the work and in a state of anxiety when performing it. In contrast, the preceptor worked as usual, but was concerned that the preceptee was not able to match this pace. The preceptor felt that the preceptee's work was slower than the required pace.

\section{Pair D}

\section{Preceptee}

"The routine was too busy for me to keep up with, and I had to do my daily work. It was common to work overtime until 8 or $9 \mathrm{pm}$. I wish I had been taught nursing skills hands-on. Once I had learned how to perform a bed bath; I was forced to do it alone. I was never given a checklist to confirm my skills, and if I said I could do it, I was forced to do so alone."

Preceptor

"It was the first day I worked with her/him. I walked with the her/him to the patient room, but when I turned around, she/he was not following me. She/he and I did not have the same flow of time or did not match or (she/he) was very slow, and I wondered if it was okay. She/he is quiet and does not talk unless I talk to her/him, so I was a little confused about dealing with someone with that personality. When I thought that I could do things at this pace, or that other new nurses could do things at this pace, I compared myself to her/him, recognizing that she/he was slow. It takes me a long time to do each thing with her/him, and I think I am not quite to the point."

Sub-theme (3): Differences in perceptions of procedures for learning

Both pairs were aware that the preceptee was working hard to learn the job. However, the preceptee did not think that the learning was time-consuming and presumed, on the contrary, that trying to find a way to remember things in an organized way is not an advisable way to learn. In contrast, the preceptor recognized that the preceptee's learning method was not appropriate, and that concepts, unless stored in an organized manner, cannot be retrieved from memory.

\section{Pair A}

\section{Preceptee}

"I told one staff member that it took me about five hours to learn, and he asked, 'Why does it take you five hours to do that?' When I told him, 'This will take you about 20 minutes to learn,' he said, 'That takes five minutes, doesn't it?" He said, "No, I do not think so. I was trying my best to remember, but it seemed to take me four times longer than others. I used to think that being to the point was not a very good thing, but I thought that is what you need to do to get a lot done." 


\section{Preceptor}

"I have a marker line through all of my disease standards, and I have heard that she/he color-codes them as, but this makes me wonder if she/he knows what is important. Even though I told her to summarize the important points by handwriting, I often wondered if this was the point of view to summarize. It is understandable that she/he did not know because it was his first time, but he did not remember what I taught, and she/he did not remember if he wrote it down or not. If he had considered it important and written it down, he would remember it, but she/he did not, or perhaps, he could not recall it from of memory. I was patient with him at first, but then I got frustrated, and then I just gave up."

\section{Theme 2: How to direct preceptee's awareness (attention) during work}

\section{Definition of Theme 2}

It is important to maintain a broad perspective in nursing clinical work, such as planning ahead for the next step and observing the overall situation. The preceptee was motivated to perform his/her work and role. Conversely, the preceptor's evaluation stated that the preceptee is distracted, neglects important perspectives, and is unable to fulfill his/her role.

Sub-theme (1): Differences in perception of focused concentration

Both pairs recognized that it was important to perform nursing tasks while taking a broad perspective and responding to situations. However, they were aware that the preceptee was not able to do so; the preceptee was overloaded with work and oblivious to her/him environment, and she did not recognize that she/he forgot something when doing something else quickly. The preceptor judged that the reasons for this were the preceptee's inability to focus on anything else besides the present task and excessive focus only on the execution of his/her work, ensuring that other things do not come into view.

Pair H

\section{Preceptee}

"I have multiple assignments where I do not do more than one care task at a time, and I am not good at that. I have never worked in an overcrowded schedule before, and I did not expect this job to be that busy. If I try to rush things, I fail, so I cannot do things quickly. But if you do not do it quickly, you will not finish. When I would be thinking about doing something and something else would come in, I would forget what I was trying to do initially; later, the staff would tell me that I had not done it, and then I would finally remember."

\section{Preceptor}

"I was very shocked when a post-op patient was complaining of pain right in front of she/he, and she/he were asking the patient if she/he was numb, and they did not think of doing something about the patient's pain. Normally, I would try to do something about the patients' pain. However, they are thinking 
about other things, or can only do one thing at a time. When I ask, 'What did the patient just say to you?' or if I ask, 'What did you say?', they say, 'I am going to go back and ask again."'

Sub-theme (2): Differences in perceptions of handling urgent situations

Both sides recognized that the preceptee was trying to respond to urgent situations as quickly as possible. The preceptee felt that it was his "role and responsibility as a newcomer" to respond to urgent tasks, and she/he tried to do so. However, the preceptor did not expect the preceptee to respond in such a way and instead, expected the preceptee to first develop the responsibility of completing his own work.

Pair F

Preceptee

"When I am in charge of a patient who needs a lot of work, I wish there was another person to help. I feel like I have to do this and that while I am doing my duties. When I have my own work to do, and the nurse call rings and says, 'It is someone from B team,' I feel like I have to go. When I heard a senior nurse in the staff room say, 'Newcomers do not see many patients, so you should at least take nurse calls,' I knew I had to. In my head, I know I do not have the time to do that. It is not my patient, and I do not really want to go, but I think the new guy has to go."

Preceptor

"When I ask someone to run an errand, she/he takes the initiative but the rest of the staff is worried if she/he can manage it. I try to talk to she/he on the assumption that she/he has finished her/him work, but I have to check first. I need to be sure. I can do what I say, and I can order the care and duties, but if there is a sudden event or I help someone else, I forget about myself. I am often so focused on what I am doing that I do not do my own things. She/he does not mind being asked to do things, so she/he takes the initiative, but when that happens, she/he inevitably neglects her own tasks."

\section{Theme 3: The ability of the preceptee to apply knowledge}

\section{Definition of Theme 3}

In clinical nursing practice, it is important not only to recall and understand what has been learned, but also to think in terms of application from learning to practice. Preceptee and preceptor both recognized that knowledge at the level of recall using a textbook was not an issue for the preceptee. However, the preceptee did not know how to apply that knowledge to practice and was instead focused on increasing the hours of study. In contrast, the preceptor felt that the preceptee's knowledge is limited to the textbook and not connected to the patient's clinical condition.

Pair F

Preceptee 
"Studying is not my weakness; I can do it if I try, but I often cannot use it (factual knowledge) in patient assessment and practice. When asked by the preceptor, 'What is your reasoning? 'I can tell that the patient has a symptom, but I cannot make a care plan."

\section{Preceptor}

"I think she/he is fine and able to do. I can sit in front of the computer (nursing record) and say, 'What about this observation item?' or 'Is this associated factor correct?' I would say, 'Oh, this is it. No, it is not. I think you know what I am talking about. But I cannot apply it to practice, and I often cannot do it with my patients."'

Pair B

Preceptee

"I study because I think I am not good enough, but I cannot apply the knowledge in my head to what I am doing. Even if I study, I cannot make use of it; it is like a spiral. I try my best, but there are patients from many different departments (in the ward); so, no matter how much I study every day, I cannot keep up. I do not feel like I am nursing, but rather just doing what I am told on the spot. (The preceptor) told me that what I am doing and what I am studying are not connected and I understand that, but I do not know how to connect them."

Preceptor

"I encouraged her/him to look back at today's patient and draw a related diagram, but I got back a diagram that was so far removed from the current problem that it looked like something from a textbook. The report was quoted directly from the textbook and copied verbatim."

\section{Theme 4: Self-evaluation ability of preceptee}

Definition of Theme 4

In nursing clinical practice, the ability to accurately self-evaluate is important for advancing and deepening learning. In the review and evaluation of the preceptee's practice to date, the preceptee stated that there are no problems in learning and growth. In contrast, the preceptor was concerned that the preceptee had not sufficiently mastered the skills to be able to function independently.

Sub-theme (1): Differences in evaluations of my growth as a learner (satisfied with my growth)

Both parties have been working very hard in their nursing clinical practice. The preceptee mastered nursing skills through practice, did not feel clumsy, and had a relatively high self-evaluation. However, the preceptor's evaluation of the preceptee's skills was low; the preceptor continuously monitored the preceptee due to unsurety about the preceptee performing nursing skills without supervision. 
Pair H

Preceptee

"I think I was able to take blood samples after doing it a few times, rather than being taught. As for the finer techniques, that is how I got better at most of it. The manual skills were not that much of a problem."

Preceptor

"She/he had mastered very few nursing skills and I was worried about letting her/him work independently because sometimes she/he could use the intravenous drip and infusion pump, but sometimes she could not. There were times when I wondered why she/he could not do something today that she/he could yesterday. The blood collection was almost independent in the second half (of the year), but I was continuously supervising because there was always something that would be left out."

Sub-theme (2): Differences in the evaluation of actual work performance (low evaluation standards for new nurses)

We recognized that both parties had been working very hard in their nursing clinical practice. The preceptee was unaffected by the fact that she/he was being properly taught nursing skills and felt that she was growing. The preceptor, in contrast, perceived no growth in the preceptee's nursing skills and was embarrassed by the staff's ridicule of slow growth.

Pair G

Preceptee

"I was taught the techniques whenever required from time to time, and I did not have that much trouble because of my training, so I did not have any difficulty with them. I think I adequately managed the procedures."

\section{Preceptor}

"I was asked to take the same patient the next day because I could do it yesterday. However, it was reset, or rather, there were times when I forgot the next day even though the skill was done the day before. When no signs of progress (in nursing skills) were shown, the people around me started to wonder, 'How are you going to teach them?"'

Theme 5: The nature of communication in the learner-instructor relationship

Definition of Theme 5

Communication (reporting, communication, and consultation) with other staff members is important when there is uncertainty about how to perform a task. The preceptee does not feel that there was a 
problem with his way of communicating. The preceptor, however, felt that the preceptee's way of communicating as a learner is not satisfactory.

Sub-theme (1): Differences in attitudes toward learning in learner-instructor relationships

The preceptee never had any problems with interpersonal relationships. However, preceptors felt uncomfortable that the preceptee did not exhibit a learner-appropriate attitude and pretended to understand even though that was not the case.

\section{Pair I}

\section{Preceptee}

"I thought I had no problems with it (communication). I do not remember ever having that much trouble with interpersonal relationships either."

\section{Preceptor}

"When I am talking to her/him, her/him reaction is always different than what I expect from a preceptee. When I provided advice in an educational capacity, the other new nurses would respond 'yes,' she/he would respond 'yes, I knew that.' So, I thought she said so because she/he was advised something she/he knew, but she/he did not know."

Sub- Theme (2): Differences in perceptions of how to check operations

The preceptees paid attention to the preceptor to know when to report work and how to react. In addition, they found it difficult to respond to a preceptor's inconsistent responses.

However, while the preceptor acknowledged the preceptee's hard work and desperation, the preceptor perceived that important information was not communicated. The preceptor did not know how to respond to the preceptee, and the responses became more withdrawn.

\section{Pair J}

\section{Preceptee}

"If I say, 'I am going to go do this,' and you answer, 'Well, I will do some other work while you doing that,' it would go relatively smoothly. I do not know whether you can hear me or whether I am getting through to you while I am looking at the (computer) screen, but I am not sure whether I should say it again. I thought the preceptor was concentrating, so when I said it again, he sometimes would reply, 'I heard you earlier.' Another time (in the middle) I did not get a response, but I tried to go with the idea that he heard me (because of the last time), and he said, 'If I did not respond, then he did not hear me, so it is like (you) did not say it."' 
"She/he greets me well and asks me anything freely, but sometimes important things are left out; so, I feel like, 'What are you saying every single time?' I can tell that they are desperate and want to do their best. However, since they are missing something important, they are spinning their wheels, they cannot do even the most trivial duplication of work, and they do not know what to do first. I do not know what to do first, and tend to be hard on them."

\section{Theme 6: Conducting business in a collaborative manner}

\section{Definition of Theme 6}

In the same ward, it is important to perform tasks in a collaborative manner. However, the preceptee was self-directed and had little awareness of working with the team and supervisor. Conversely, the preceptor was a member of the team and had a high sense of collaboration, and this was also expected of the preceptee.

Sub-theme (1): Differences in perceptions of the significance of asking for help from the team

The preceptee believed that when a problem arose, she/he would solve it without asking for help. At the root of this was a desire to not be considered inferior. The preceptor, however, perceived that the preceptee's inability to seek help was due to a lack of understanding of the impact on patients and their needs.

Pair G

\section{Preceptee}

"I thought I had to (figure it out myself), so I thought I could not just say, 'I do not know,' or 'I have never done it before.' I mean, I did not think of asking. The preceptor said to me, 'If you have never done it before, you have to tell me, right? Do you understand?' I said, 'I don't know,' and preceptor said, 'You have to tell me what you do not know, don't you? I do not know. However, you are still at this level.' I could not say it because I was afraid of what would happen if the preceptor thought that I was still at this level."

\section{Preceptor}

"I told her/him to call someone on the nurse's call when the patient got up from the wheelchair on the bedside table, but I do not know if everyone was too busy to call, or if she/he did not call, but she/he started to help the patient herself. The patient had a deteriorated cognitive condition, and the chair was placed in a halfway position. So, I told her/him, 'That kind of thing is scary,' and she/he cried a lot, so I thought that she/he understood how scary it was (to assist alone) and the need to report it."

Sub-theme (2): Differences in interpretation of team collaboration

The preceptee was unappreciative of other staff members shouldering the work he was unable to do. Conversely, the preceptor coordinated the work behind the scenes so that the preceptee was not 
overburdened. However, she/he felt pressure from her/his staff, which resulted in more work for her/him, and she/he felt that he was burdening her/his staff with more work.

Pair A

Preceptee

"I think the pair probably did a lot of work, but they did a lot of things that I did not do, and I was thought, 'Oh, it was over before I knew it."'

\section{Preceptor}

"She/he was taking so much time to get basic information about the patients. She/he would drastically reduce her/his duties or fix the duties and tell her/him to focus only on that. I told them to return to the station at 4:00 (in the evening) so that there would be no overtime. It might have been difficult for the staff around me because they had to take on that much work. So, I felt that (the other staff) had an atmosphere of not wanting to be under my guidance."

\section{Discussion}

This study explored the differences in perceptions regarding the clinical practice of nursing between preceptors and their preceptees, who did not make progress in workplace adjustment during nurse education; six themes were identified.

After interviewing both sides, it became clear that the same event was interpreted differently depending on their positions, perspectives, and contexts. As the preceptees were nurses who had left or had been transferred, the existence of these differences in perceptions suggests that these factors may have an impact on their departure or transfer. However, we do not aim to place blame on one side or the other for the preceptee's turnover or transfer and would like to consider effective support not only for the preceptee but also for the preceptor.

(1) From the perspective of preceptors

The preceptor tended to ascribe the cause of the preceptee's poor performance to the preceptee alone. In other words, the preceptor tended to attribute the preceptee's inability to perform to internal factors such as personality traits, ability, and effort-a fundamental attribution error [19]. Furthermore, the educational repertoire did not match the individuality of the preceptee. For example, if there was no growth in the preceptee, Theme 1, Sub-theme (1), preceptors attributed preceptees' inability to clumsiness, or to their nature or personality; Theme 1, Sub-theme (2), preceptors tended to use "self" or "nurses in charge of education in the past" as the standard and then rated preceptees as not able; Theme 6, Sub-theme (3), measures to reduce the workload of preceptees have been attempted, but it is hard to say find an effective way to educate preceptees. 
In a survey conducted by Gregg et al., the most common difficulty for new nurse educators in fulfilling their role in nurse education was "teaching to meet individuality [13]." The preceptor in this study did not give due consideration to the individuality of the preceptee and erred in addressing the most significant area of development. Therefore, it is necessary to prepare several educational methods and scaffolds that can be adapted to the individuality and diversity of preceptees, especially nurses who grow slowly, and to train preceptors and educators in these methods.

The preceptor is disappointed with the preceptee's poor performance, and negative feelings are associated with it. This suggests that preceptors and preceptees influence each other's relationship. The preceptor gives negative evaluations to the preceptee because the preceptee "cannot do" more than he imagined, and this also causes negative emotions. For example, Theme 4, Sub-theme (2), Feeling uneasy about preceptee. Furthermore Theme 1, Sub-theme (3), Theme 5, Sub-theme (2), the preceptor is frustrated.

The preceptor understands that the preceptee is not able to do his work, but experiences negative affect because he is not able to do it as well as imagined (mood congruent effect) [20]. The preceptor understands that the preceptee is unable to perform the task, but experiences negative affect because the preceptee is unable to perform the task as expected. As a result, the preceptor's attitude may become harsher, and it may become difficult to maintain a good preceptor-preceptee relationship. As a result, an irreversible misalignment of the mutual relationship was identified. To prevent deterioration of the mutual relationship between preceptors and preceptees, training in emotional control (e.g., anger management) may be necessary [21] to prevent deterioration of the relationship between the preceptor and preceptee.

In addition, the importance of developing a human resource environment in the workplace that is conducive to and supports the education of preceptors was clarified. Theme 4, Sub-theme (2), Theme 6 , Sub-theme (2), The staff takes the position that they do not want to be involved, leaving the preceptor to educate the preceptee as if they were someone else.

Despite this, they feel that the responsibility of failure in educating the preceptee is placed solely on the preceptor. Hyrkas et al. found that in the relationship between the preceptor and the preceptee, when the preceptor is in a situation where his efforts are rewarded, the preceptee's satisfaction also increases and the preceptor's commitment to the role is strengthened [15]. Therefore, it is important to review the support system for preceptors and foster a culture of human resource development in the workplace.

(2) From the perspective of a preceptee

preceptees seemed to blame their inability to perform their own work because they were not sufficiently educated. Theme 1, Sub-theme (2), they do not check the techniques with a checklist, and once you have experienced them, you are encouraged to be independent the next time. Theme 4, Sub-theme (2), this can be seen from her statement that she has been able to do this in her nursing clinical practice rather than being taught. This is due to the self-serving bias [22], in which one's own actions are reasoned in one's 
own favor, and the preceptee places the blame for her inability on external factors (attribution), namely, that she was not properly taught by the preceptor.

In Theme 4, it was found that the preceptee's self-evaluation tended to be higher than the preceptor's evaluation of work performance. Theme 6, Sub-theme (1), The preceptee had never felt the need to communicate or build interpersonal relationships, and it seemed as if this was a difficulty he had only faced when he entered the workforce.

It can be said that this preceptee experienced the Dunning-Kruger effect [23], in which people with lower abilities tend to estimate their own abilities more highly. Furthermore, in Theme 1 Sub-theme (1) and Theme 6 Sub-theme (1), the preceptee is impatient and does not want to admit that he or she is not able. This is the self-evaluation maintenance motive, which is a universal basic motive for human beings to maintain their own evaluation [24]. In this self-evaluation maintenance model, in order to avoid selfevaluation, people maintain psychological distance from others who have high performance levels (in this case, the preceptor). As shown in Table 1, the preceptee may seek psychiatric treatment due to maladjustment in the workplace or personal relationships. Therefore, it is necessary for the preceptor and the preceptee to build a trusting relationship by collaboratively discussing goal setting and learning methods under an educational alliance [25]. For example, using the R2C2 model [26] may be recommended as a model that can resolve the mutual relationship through collaborative feedback and coaching.

\section{Limitations of the study and future directions}

The present study has several limitations: it was difficult to ask both the preceptor and the preceptee to reflect on the same past events and situations, and therefore, we could not match them to the same situations. In addition, since the data were collected at a limited number of sites, caution should be exercised when applying the results to other contexts-the relationship between preceptees and preceptors is not easily generalized.

As a question for further research, the relationship between the preceptor and their preceptee who has shown appropriate growth as a nurse should also be explored.

\section{Conclusion}

In this study, six thematic cognitive differences were identified between preceptees and preceptors regarding the clinical nursing practice of preceptees who were not well adjusted to the workplace. These six themes were found to be caused by differences in the perspectives and evaluation criteria of both parties. It is necessary to examine nurse education on the premise that such differences may occur depending on the position and role of nurses in the workplace, and to look at curricular framework changes to bring in a systemic influence towards the training of young nurses. 


\section{Declarations}

\section{Ethics approval and consent to participate}

This study was approved by the Institutional Review Board of Gifu University. (Approval Number 25-385). Informed consent was obtained from all participants. All methods were carried out in accordance with the Declaration of Helsinki.

\section{Consent for publication}

Not applicable

\section{Availability of data and materials}

The data supporting the conclusions of this study are not publicly available in order to maintain the privacy of the participants' educational records in the workplace, but are available from the corresponding author on reasonable request.

\section{Competing interests}

The authors declare that they have no competing interests.

\section{Funding}

This study was supported by the JSPS KAKENHI Grant-in-Aid for Young Scientists Number18K13192Not applicable

\section{Authors' contributions}

CK carried out this study, performed a qualitative analysis and drafted the manuscript. RI participated a discussion of the final themes until a consensus was reached. TS conceived of the study, and participated in its design and coordination and helped to draft the manuscript. All authors read and approved the final manuscript.

\section{Acknowledgments}

We would like to express our deepest gratitude to all the preceptors and preceptees who participated in this study.

\section{References}

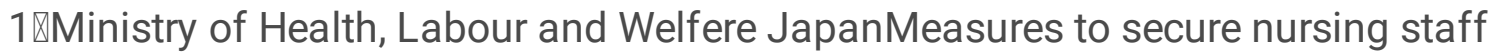

https://www.mhlw.go.jp/stf/seisakunitsuite/bunya/0000095525.html $\llbracket A c c e s s e d ~ 10^{\text {th }}$ January 2022】 
2) WHO, Nursing and midwifery

https://www.google.com/search?

rlz=1C1GCEU_jaJP903JP903\&sxsrf=ALeKk03AAOqrZsVhQj1alPCZG4vE7404dg\%3A1596675199023

\&ei=f1QrX859rLaYBauCrlgH\&q=who+nurses+shortage\&oq=who+nurses+s\&gs_lcp=

CgZwc3ktYWIQARgAMgQIABAeMgYIABAIEB4yBgAEAgQHjIGCAAQCBAeMgYIABAIEB

4yBgAEAgQHjoHCCMQsAMQJZoHCAAQsQMQBDoECAAQBDoCCAA6BAgAEBM6BggAEB

4QE1DMIli4RWCkV2gBcAB4AIABVogB8wSSAQE4mAEAoAEBqgEHZ3dzLXdpesABAQ\&sclient=psy-ab

$\triangle$ Accessed $10^{\text {th }}$ January 2022》

3) Han $\mathrm{H}$. The study on the actual conditions of the nurse shortage in Japan. Journal of east Asian studies.2012;10:1-24.

4) Ministry of Health, Labour and Welfare: Current status of training for new nursing staff

https://www.mhlw.go.jp/shingi/2009/04/dl/s0430-7b.pdføAccessed $10^{\text {th }}$ January 2022

5) Chan Z. C. Y., Tam W.S., Lung M. K. Y., Wong W.Y, Chau W.Y.. A systematic literature review of nurse shortage and the intention to leave. Journal of nursing management. 2013;21(4): 605-613.

6) Flinkman M., Laine M., Leino-Kilpi H., Hasselhorn H.-M., Salanterä S.. Explaining young registered Finnish nurses' intention to leave the profession: a questionnaire survey. International journal of International journal of nursing studies. 2008;45(5): 727-739.

7) Katagiri M, Sakae C. A literature review on the factors about turnover and continuing of nursing profession for new graduate nurses. Journal of nursing research Saku University.2016;8(1):49-59.

8) Uchino K, Shimada R. Literature review on the leaving of newly nurses in Japan. The Japan Society of Health Sciences of Mind and Body. 2015; 11(1): 18-23.

9) Watanabe R., Arakida M., Shimizu Y., Suzuki S.. Predictors on personnel Turnover among Japanese Yyoung Nurses. The Journal of the Japan Academy of Nursing Administration and Policies. 2011;15(1):17-28.

10खEunhee L.. Why newly graduated nurses in South Korea leave their first job in a short time? A survival analysis. Human resources for health.2019;17(1): 61.

11) Ogawa T., Hayashi T., Imura K.. Characteristics, Training, and Support of Nurses Identified as having "Slow Progress" during Professional Development. Japan Society of Nursing Research. Japan Society of Nursing Research Journal. 2016;39(5):65-74.

12) L'Ecuyer, K. M. Perceptions of nurse preceptors of students and new graduates with learning difficulties and their willingness to precept them in clinical practice (Part 2). Nurse education in practice.2019;43: 210-217. 
13凶Hirano R., Koyama M.. Novice Preceptors' Difficulties with Clinical Instructions for Newly Graduated Nurses, their Behaviors and Support Needs to Overcome these Difficulties. Journal of Japan Society of Nursing Research.2018;41(5): 971-981.

14)Gregg F.M., Yagi K., Tamada M., Maeda C., Kawato M., Hayashi C., Tsurushima H., Kobayashi Y., Kawamura T., Okayama T., Tanaka T.. Support for Clinical Nurse Educators in Teaching Newly Hired Nurses. Bulletin of Kobe City College of Nursing Kobe City College of Nursing.2016;20: 5-13.

15) Kristiina H.E., Linscott D.A., Rhudy J. P. Evaluating preceptors' and preceptees' satisfaction concerning preceptorship and the preceptor-preceptor relationship. Journal of Nursing Education and Practice.2014;4(4): 120.

16) Quek G. J.H., Ho G. H.L., Hassen N. B., Quek S. E.H.. Perceptions of preceptorship among newly graduated nurses and preceptors: a descriptive qualitative study. Nurse education in practice. 2019;37: 62-67.

17) Japanese Nursing Association's (JNA) Clinical Ladder the Japanese Nursing Association's (JNA) Clinical Ladder

https://www.nurse.or.jp/home/publication/pdf/fukyukeihatsu/ladder.pdf $\bigotimes$ Accessed $10^{\text {th }}$ January 2022

18) Braun V.V., Clarke V.V.. Using thematic analysis in psychology. Qualitative Qual research Res in Ppsychology. 2006; 3(2):77-101.

19) Ross L.. The intuitive psychologist and his shortcomings: Distortions in the attribution process. Advances in experimental social psychology. California: Academic Press; 1977.

20) Forgas J. P., Stephanie M.. After the movies: Transient mood and social judgments. Personality and social psychology bulletin.1987;13(4): 467-477.

21) Gonnelli C., Raffagnino R., Puddu L.. The emotional regulation in nursing work: an integrative literature review and some proposals for its implementation in educational programs. IOSR Journal of Nursing and Health Science.2016;5: 43-49.

22) Miller D. T., Ross M. Self-serving biases in the attribution of causality: Fact or fiction? Psychological Bulletin.1975; 82: 213-225.

23) Justin K., Dunning D.. Unskilled and unaware of it: how difficulties in recognizing one's own incompetence lead to inflated self-assessments. Journal of personality and social psychology.1999;77(6): 1121-1134.

24) Abraham T.. Toward a self-evaluation maintenance model of social behavior. Advances in experimental social psychology. 1988;21:181-227.. 
25) Summer T., Ajjawi R., Regehr G.. The "educational alliance" as a framework for reconceptualizing feedback in medical education. Academic Medicine.2015:90(5): 609-614.

26) Sargeant J, Lockyer J. M., Mann K., Armson H. Warren A., Zetkulic M., Soklaridis S., Könings K., Ross K., Silver I., Holmboe E., Shearer C., Boudreau M..The R2C2 model in residency education: how does it foster coaching and promote feedback use? Academic Medicine.2018;93(7): 1055-1063.

\section{Tables}

Table 1 The status of preseptees and preseptors

pair Preseptee's situation and experience

Education experience as a Preseptor

A Second year working as a nurse, transferred from another hospital, planning to retire

Second time in charge of a rookie.

B Second year on the job, department transfer in the middle of the first year, scheduled to retire

Second time in charge of a rookie.

C Third year as a nurse, transferred to a different department in the middle for the first time of the first year, considering retirement, seeing a psychiatrist

D 5 years on the job, transferred to a different department in the middle of the first year and continued to work there, saw a psychiatrist

Second time in charge of a rookie.

E Second year of service

for the first time

F Third year of service

Multiple rookie assignments

G Retired after 2 years of service and will be transferred to another hospital

Multiple rookie assignments

H Retired after 3 years of service and will be transferred to another hospital

I Two years on the job, with psychiatric consultation.

for the first time

$\mathrm{J}$ Two years on the job, seeing a psychosomatic doctor.

for the first time

Table 2 Emergence of a theme for each pair 
pair Theme 1 Theme 2 Theme 3 Theme 4 Theme 5 Theme 6

\begin{tabular}{|c|c|c|c|c|c|c|}
\hline$A$ & ૫ & & & Q & ૫ & ૫ \\
\hline$B$ & & & ૧ & & & 口 \\
\hline$C$ & ૫ & & & Q & ए & \\
\hline$D$ & ૫ & & & & 口 & \\
\hline$E$ & ૫ & & प & ( & ૧ & \\
\hline$F$ & ૫ & ૧ & प & & ૧ & \\
\hline$G$ & ૫ & & & ૧ & ૧ & \\
\hline $\mathrm{H}$ & ૫ & ૧ & & Q & प & Q \\
\hline I & & & ૧ & ૧ & ૧ & ૧ \\
\hline $\mathrm{J}$ & ૧ & & ૧ & & ૧ & — \\
\hline
\end{tabular}

